\title{
Semejante adjetivo es semejante. Sus valores en español actual
}

\author{
Semejante is such an adjective. \\ Its values in Modern Spanish
}

\section{ENRIQUE PATO}

Département de littératures et de langues du monde. Université de Montréal, Canadá Correos electrónicos: enrique.pato-maldonado@umontreal.ca; enriquepato@hotmail.com

El presente trabajo se centra en la descripción gramatical del adjetivo semejante en español actual, esto es, en mostrar sus valores y usos. En cuanto a su posición con respecto al sustantivo, como adjetivo calificativo suele aparecer en posición posnominal y tiene un valor restrictivo (caso semejante); como adjetivo clasificativo-determinativo, aparece -en cambio- en posición prenominal (semejante caso). El significado de 'grande' (semejante animal), limitado en principio a un solo país (Honduras), es posible registrarlo en otras variedades del español actual, especialmente en el habla de los jóvenes. Por otro lado, su recategorización como adverbio es idéntica a la de los adjetivos parecido e igual. Esta conversión, en apariencia nueva en el espańol actual, se registra desde el espańol antiguo.

Palabras clave: Gramática española, variación, corpus lingüísticos, adjetivo, semejante

This paper focuses on the grammatical description of the adjective semejante in Modern Spanish; this is to show their values and uses. As for its position in relation to the noun, as a qualifying adjective it usually appears in posnominal position and has a restrictive value (caso semejante); as assortativedeterminative adjective, it appears -however- in prenominal position (semejante caso). The meaning of 'big' (semejante animal), limited in principle to a single country (Honduras), it is possible to register in other varieties in Modern Spanish, especially in the speech of young people. Furthermore, their reclassification as an adverb is identical to that of similar and igual adjectives. This conversion, apparently new in Modern Spanish, is recorded in Old Spanish.

Key words: Spanish grammar, variation, linguistics corpora, adjective, semejante 


\section{INTRODUCCIÓN Y OBJETIVOS}

En español actual, y según el Diccionario de la lengua española (RAE 2017), el adjetivo semejante presenta dos valores y tres usos posibles: uno clasificativo, con el significado de 'que semeja o se parece a alguien o algo' (Una densidad semejante a la masa) y otro comparativo-ponderativo (No es lícito valerse de semejantes medios), y como determinante, con carácter de demostrativo, equivalente a tal (No he visto a semejante hombre) (RAE/ ASALE 2009: 1326).

Por otro lado, como indica el Diccionario de americanismos (ASALE 2010) para el caso concreto del español de Honduras, este adjetivo también presenta el sentido de 'grande, enorme'.

De este modo, el significado de este adjetivo en unas ocasiones se acerca al de 'similar, parecido e igual', como en (1a) una olla semejante ('una olla parecida, similar') y en otros contextos toma el significado de 'tal' ("tal significa lo mismo que semejante", señalaba ya Bello 1883: 116), como en (1b) en semejante olla ('en tal olla'). Además, cada vez con mayor frecuencia y no solo en Honduras, se registra con el sentido de 'grande, enorme', como en (1c) semejante olla ('una olla grande, enorme' en la que caben muchos frascos) ${ }^{1}$ :

(1) a. Coger la cebolla y trocearla en trocitos que sean pequeños pero finos. Ahora en una paellera o una olla semejante, echaremos aceite de oliva y pocharemos los trocitos de cebolla... («Paella rápida de calamares y mejillones», Cocina ahorro.net, 05/04/2013, España).

b. La Guardia Civil se ha convertido en semejante olla a presión que hasta los mandos no dudan en movilizarse por sus derechos en la capital. Un centenar de representes y delegados provinciales de los sindicatos AUGC y Unión de Oficiales alzaron carteles contra los recortes impuestos por el Ministerio ( El desafío de la Benemérita: "Interior no nos amordazará”", El Correo gallego.es, 08/09/2010, España).

c. Tengo un frasquito en la heladera pero no parece como el tuyo, ¿hay que tener semejante olla para cerrar al vacío o se podrá hacer de a uno? («Hice un poco de escabeche», Foro FullAventura.com, 21/06/2011, Argentina).

El objetivo de este trabajo de carácter gramatical es ofrecer una descripción general de este adjetivo -tal y como es empleado hoy en día-, presentar algunas de sus propiedades

\footnotetext{
$1 \quad$ La fuente de los ejemplos registrados es variada e incluye los corpus lingüísticos del CREA (Corpus de referencia del español actual), CORPES XXI (Corpus del Español del siglo XXI), Corpus del español, COSER (Corpus Oral y Sonoro del Español Rural) y COLEM (Corpus oral de la lengua española en Montreal), prensa en línea española e hispanoamericana, blogs personales y foros de discusión. En cada uno de los ejemplos presentados figura el título (en el caso de los ejemplos de prensa el titular y en los literarios la obra), el nombre del periódico, el autor, la fecha de publicación y el país, siempre que ha sido posible recuperar todos estos datos.
} 
gramaticales y ampliar, en su debida forma, la extensión geográfica y la documentación ofrecida por la gramática y los diccionarios académicos ${ }^{2}$.

\section{CARACTERIZACIÓN GENERAL DE SEMEJANTE}

Como vimos en el apartado precedente, en función del contexto en el que aparece, el adjetivo semejante puede ser calificativo y expresar una propiedad (dos personalidades semejantes) o ser clasificativo-descriptivo (dos triángulos semejantes) (RAE/ASALE 2009: 967). La paráfrasis 'perteneciente o relativo a' se puede aplicar a los adjetivos clasificativos (RAE/ASALE 2009: 980 y 985), por lo que en el caso concreto de semejante estaríamos ante lo 'relativo a la semejanza'. En este caso semejante restringe la denotación del sustantivo al que acompańa, pero esa restricción no aparece especificada.

El significado de identidad de semejante cuando antecede al nombre equivale al del grupo un/una + nombre + como eselesa pero también a un/una + nombre + asi (cf. Bello 1883: 116, RAE/ASALE 2009: 967). De este modo, semejante carga en (2a) equivaldría a una carga como esa y semejante alfombra en (2b) a una alfombra asi. La posición prenominal, como en los determinantes, es la habitual en este adjetivo.

(2) a. Ciertamente lo suyo era solamente un presentimiento, no tenía argumentos para demostrar que los muros del padre Forcada no soportarían el peso, ni siquiera sabía con certeza si Forcada previó o no semejante carga en la cubierta (Donde ladrón no llega, Luis Hernáez, 1996, Paraguay).

b. Desde la tribuna es un tapete verde. Liso, regular, aterciopelado, estimulante. Desde la tribuna quizá crean que, con semejante alfombra, es imposible errar un gol y mucho menos errar un pase ("El césped", Cuentos de Fútbol, Mario Benedetti, 1959, Uruguay).

La posición, por tanto, es clave para la correcta interpretación de este adjetivo (RAE/ASALE 2009: 1326). En efecto, como prenominal determinativo equivale a 'tal' (cf. 3a semejante cosa y 3c semejante ansiedad) y como posnominal clasificativo a 'similar' (cf. 3b cosa semejante y $3 \mathrm{~d}$ ansiedad semejante):

(3) a. Por qué no le das unas vacaciones, para que se entone un poco. - - ¿Vacaciones a Camacho? -se espantó el empresario progresista-. ¿¿́l te ha pedido semejante

\footnotetext{
2 Este trabajo ha sido parcialmente financiado por el Fonds général de la recherche (FGR) de la Universidad de Montreal para el proyecto de investigación «Syntaxe dialectale de l'espagnol». Mi agradecimiento a Inés Fernández-Ordóñez (Real Academia Española/ Universidad Autónoma de Madrid) por la lectura que realizó de la versión preliminar y por sus atinados comentarios. Asimismo, mi agradecimiento a los revisores anónimos de la revista por todas sus sugerencias y la retroalimentación recibida.
} 
cosa? Le dije que no, que era una sugerencia de sus colaboradores (La tía Julia y el escribidor, Mario Vargas Llosa, 1977, Perú).

b. Toma, entérate, dijo, y me tendió unos cuantos impresos con ilustraciones a todo color. ¡A mí no me interesan estas pavadas!, me atreví a decir en voz alta. ¡Nunca me interesaron las comodidades domésticas ni cosa semejante! (Puerta, Yula Riquelme de Molinas, 1994, Paraguay).

c. "Un día -agregó- ha de aparecer el dueño de esa fortuna, y sólo él podrá desenterrarla". Nadie sabía por qué un hombre que siempre fue tan desprendido había empezado a codiciar el dinero con semejante ansiedad, y no las modestas cantidades que le habrían bastado para resolver una emergencia (Cien años de soledad, Gabriel García Márquez, 1967, Colombia).

d. Hombres expertos en trastornos de amor, probados en el mundo entero, afirmaban no haber padecido jamás una ansiedad semejante a la que producía el olor natural de Remedios, la bella. En el corredor de las begonias, en la sala de visitas, en cualquier lugar de la casa, podía señalarse el lugar exacto en que estuvo (Cien años de soledad, Gabriel García Márquez, 1967, Colombia).

Sin embargo, en algunas ocasiones esta distinción entre los valores prenominales y posnominales no es tan evidente, y solo el contexto permite una distinción clara entre ambos significados. En los ejemplos de (4), donde como es habitual no aparece el término de la comparación, los dos ejemplos podrían parafrasearse como 'casos de ese tipo', 'casos con esas características' o 'tales casos':

(4) a. Todas las ceremonias son cumplidas por cualquiera de esos personajes, en forma pomposa y observando el más mínimo detalle de cuanto se acostumbra en semejantes casos. Algunas veces el jefe suele hacer estas prácticas (Medicina andina, Jorge Lira, 1985, Perú).

b. Yolanda creía a veces que iba a estallar, que su contenida pasión la llevaría a cometer cualquier locura de esas que suelen cometerse en casos semejantes, y no hallaba la forma de sentirse tranquila (Sólo cenizas hallarás, Pedro Vergés, 1980, República Dominicana).

Esta falta de distinción semántica ('tal' vs. 'similar') es antigua en español (cf. 5), y es posible que venga dada por la interpretación específica o inespecífica del sustantivo que complementa y por la interpretación como adverbio del adjetivo, tal y como veremos más adelante. Además, como señala la RAE/ASALE (2009: 998) para el caso de los adjetivos intersectivos, la posición prenominal adquiere una interpretación adjetival no restrictiva (un viejo amigo) y la posnominal una interpretación restrictiva (un amigo viejo).

(5) a. Otro semejante enxienplo ay que cuenta seneca enlas sus epistolas en commo alexandre el grande denosto mucho asus amigos lisonjeros que le 
estauan deziendo que era fijo de jupiter (Castigos e documentos de Sancho IV, ss. XIII-XIV).

b. Otro exemplo semejante fue en Habraím con el grand turco Selín y con Solimán gran turco su hijo. Este Habraím fue de un lugarejo de Albania que se llama Parga (El Libro de los proverbios glosados, Sebastián de Horozco, 1544).

Por otro lado, como indica la Nueva gramática de la lengua española (RAE/ASALE 2009: 1326), el valor anafórico aparecería en semejante (equivalente a tal) sobre todo en interrogaciones retóricas (¿Qué puede esperarse de un país semejante?) y en contextos negativos e irreales (No me vengas ahora con semejantes pretensiones) ${ }^{3}$. En este uso como demostrativo semejante también puede equivaler a eselesa y a estelesta con una interpretación cualitativa (No he visto a semejante hombrel No he visto a ese hombre), como vimos en los ejemplos de (2). En estos casos adquiere el sentido de 'un X como este' o 'un X de ese tipo': No pensé que pudiera decir semejantes/ tales/ esas tonterías, que alterna con No pensé que pudiera decir tonterías como esas.

Retomando la información del Diccionario de americanismos que presentamos en el $₫ 1$ para el caso de Honduras, los ejemplos siguientes muestran los tres valores del adjetivo semejante cuando aparece antepuesto al nombre. En (6a) semejante odisea se puede interpretar como 'tal odisea' o 'una odisea como esa', pero también como 'una odisea similar', en (6b) semejante bestia marina con el sentido de 'una bestia asî' (cuantificativo), y en (6c) semejante cantidad con el sentido de 'gran cantidad', 'una cantidad enorme' (cuantificativo), sin descartar 'tal cantidad':

(6) a. Presidente Juan Orlando Hernández: "Estados Unidos asume su responsabilidad, nosotros también ya hacemos esfuerzos para crear mejores condiciones de vida en nuestros países", manifestó. Y continuó diciendo: "Nadie quiere que sus hijos pasen semejante odisea... por eso le estamos apostando fuertemente al Plan para la Alianza del Triángulo Norte” («Nadie quiere que sus hijos pasen semejante odisea», El Heraldo.hn, 14/11/2014, Honduras).

b. Terror. Eso es lo que provocaría en cualquiera la aparición en las cristalinas aguas australianas de semejante bestia marina. En una de las más populares playas del país hallaron lo que podría convertirse en el tiburón azul más grande que se conozca («Terror: Semejante bestia marina de seis metros fue cazado mientras tragaba a otro», Canal 6.com.hn, 12/08/2015, Honduras).

c. "Cuando supe de esto, hablé en su momento con los presidentes de los equipos para decirles que cómo era posible que pagaran semejante cantidad y la respuesta de ellos era que tenían patrocinadores para poder hacerlo", explicó

\footnotetext{
3 Moliner (2007: 2684), por su parte, señala este uso en expresiones negativas de ponderación, pero pospuesto (Nunca habia visto una calabaza semejante).
} 
Prieto («En Honduras hay futbolistas que ganan 350 mil lempiras al mes», Diario más.hn, 01/08/2011, Honduras).

Este último significado de semejante con el sentido de 'gran, grande, que destaca' se emplea también en otras variedades además del español de Honduras; muchas veces cuando la ponderación tiene carácter despectivo (cf. Moliner 2007: 2684), o indica algo digno de desprecio.

En estos casos semejante aparece siempre antepuesto, como en (7b y c). En el ejemplo de (7b) semejante cabrón equivaldría a 'qué cabrón es el que...'. En (7c), en cambio, semejante hijo de puta se emplea con el sentido de gran 'que supera en intensidad a lo que es ser un hijo de puta' o también como '(so) pedazo (de)', simplemente para reforzar el significado del antecedente de un grupo nominal exclamativo (RAE/ASALE 2009: 3196). Pero semejante no solo se emplea con sustantivos de carácter negativo, también aparece antepuesto a sustantivos positivos, como en (7a), donde semejante pibón tiene el significado de 'una gran mujer', 'una mujer muy guapa, de nivel' o 'toda una mujer'. Todos estos casos son propios del registro popular y coloquial $^{4}$, y tienen un uso muy extendido entre los jóvenes:

(7) a. Natiforever dice: Es que es alucinante el cambio que ha pegado esta chica... todavía no se me cierra la boca!! Cómo es posible que haya pasado de ser una chica monilla a ser semejante pibón?! Lo que hace la chapa y pintura macho («Sara Carbonero», Foros Vogue.es, 16/11/2010, España).

b. Bárbara Alejandra dice: Semejante cabrón el que redactó esta noticia («Mira cómo tiemblo ", Twitter.com, 08/06/2011, Venezuela).

c. Victor dice: Al estúpido que pide fotos, mira semejante hijo de puta, respeta el dolor de los demás («Expresidente Francisco Flores sigue en estado crítico», El Salvador.com, 02/02/2016, El Salvador).

En cuanto a la construcción con preposición, semejante (con la acepción de 'similar') aparece seguido de la preposición a (cf. 8 a y b). A pesar de que en algunos trabajos (Seco 1998: 403, RAE/ASALE 2009: 3412) es la única posibilidad que se ofrece, en menor medida también puede aparecer con la preposición de (cf. 8c), solución registrada con mayor frecuencia en las variedades americanas (17 casos en total, según los datos del CORPES XXI, cf. $\$ 3)$ :

\footnotetext{
$4 \quad$ En su segunda acepción del adjetivo semejante el Diccionario del español usual en México (1996) ofrece estos dos significados: i) 'que es de gran tamaño, volumen, nivel, etc.' ("Quería que cargara semejante cantidad de maíz»), y ii) 'que es o se considera malo, insuficiente o despreciable' ("No hablaba con tipos semejantes»; «No se puede trabajar con semejante herramienta»). Una definición similar figura en el Diccionario del español de México (DEM 2016). Seco, Ramos y Andrés (1999: 4066) nos recuerdan otro uso popular y humorístico de semejante, con valor demostrativo, con intención eufemística (Le golpeó en semejante sitiol en semejante(s) parte(s)).
} 
(8) a. El reyezuelo taíno le envió con dos de sus servidores un pájaro semejante a un ave del paraíso, pero sin los colores que adornan a ésta (Vigilia del Almirante, Augusto Roa Bastos, 1992, Paraguay).

b. En todo caso el cínico no se ocupa del culto a los dioses, pues el filósofo cínico es el único que lleva una vida semejante a ellos y no tiene que reconciliarse con los dioses ni pedirles nada (Historia de la filosofía antigua, Carlos García Gual, 2004, España).

c. Este proyecto nació bajo la visión del Rev. Rodolfo Gonzales y la necesidad de brindar un espacio exclusivo para los niños donde se muestre la vida semejante de ellos («Mi Casa Feliz: Show Infantil», Bethel.tv, 13/10/2015, Perú).

Como adjetivo calificativo admite la construcción comparativa (Es más semejante a un faisán que a un pavo) (RAE/ASALE 2009: 3371), aunque suele aparecer normalmente sin el segundo término de la comparación, o simplemente precedido por el cuantificador más (elllo más semejante a):

(9) a. No es ternura o caridad, tampoco se trata de la agradable corrupción del beso recibido. Es calor. Lo más semejante que conservo en la memoria son sus besos indelebles (Las plegarias del cuerpo, Eloy Urroz, 1994, México).

b. La compañía diurna de Antuco también vino a ser estímulo de inquietudes. A la sola observación del hijo, cada día más semejante a él, cantaba en ecos la mocedad; y en muchos momentos el considerar los avances y destrezas del muchacho hacía que tales ecos gritasen como voces de alarma y citaran a cotejos (Gran señor y rajadiablos, Eduardo Barrios, 1949, Chile).

c. Venus: Es el segundo planeta del Sistema y el más semejante a la Tierra por su tamaño, masa y densidad. Sin embargo, no tiene océanos y su densa atmósfera provoca un efecto invernadero que eleva la temperatura hasta los $480{ }^{\circ} \mathrm{C}$ («Conoce el Sistema Planetario Solar», El Popular.pe, 23/11/2015, Perú).

Del mismo modo que sucede con mismo e igual (RAE/ASALE 2009: 3413), el adjetivo semejante puede formar parte de construcciones comparativas de igualdad simétricas, tanto coordinadas (Montreal y Boston son (ciudades) semejantes) como no (Montreal es (una ciudad) semejante a Boston).

El adjetivo semejante también puede comportarse como término de polaridad negativa (RAE/ASALE 2009: 3688), no necesariamente inespecífico, y así aparece precediendo a no (cf. 10a y b) y no... nunca (cf. 10c) en los siguientes casos:

(10) a. Me llama "idiota" con insoportable perseverancia. Como comprenderá, no puedo tolerar semejante trato. Sé, mi señora, que el Derecho Amoroso 
Internacional está de mi parte (Carta abierta a una pérfida, Roberto Gutiérrez Alcalá, 2009, México).

b. Ahora ordena que se absuelva a los maestros y estudiantes que hubieran incurrido en la excomunión contemplada por las prohibiciones de $1210 \mathrm{y}$ 1215, sobre los libros de filosofía natural, y dispone que en adelante no se recurra a semejante pena contra la corporación universitaria (La Prensa, $3^{a}$ edición, 01/05/1992, Argentina).

c. ¡Yo no le aconsejaré a usted nunca semejante cobardía! ¡Eso fuera apelar a un recurso hipócritamente piadoso, inventado por los escritores románticos... (El escándalo, Pedro Antonio de Alarcón, 1862, España).

Desde el punto de vista histórico, la forma más empleada fue semejable, hoy en día desusada, con el sentido de 'semejante' (cf. RAE 2017 y CORPES XXI, donde solo se registra un único caso). Como sucede con semejante, semejable podía aparecer en posición posnominal (cf. 11a 'un hombre parecido') o prenominal (cf. 11b 'otro crimen de esa categoría):

(11) a. E luego vio un ombre semejable a ssy mesmo que torcia una cuerda e levantavase de la obra e fazia oracion e despues tornava a obrar e otra vegada tornava a fazer oracion (Libro de los exemplos por A.B.C., Clemente Sánchez de Vercial, c. 1421).

b. O muy amada miedo me has causado en mj coraçon et turbaçion: sobre lo qual non puedo saber que me diga: por quanto yo mesma he incurrido en otro semejable crimen et delicto (Esopete ystoriado, s. XV).

La modificación del adjetivo semejante con sufijos apreciativos es poco frecuente, pero no imposible. En ocasiones el sufijo no aporta información cuantificativa, como en el diminutivo semejantito (cf. 12a); pero otras veces parece que la intensificación es mayor, como con el superlativo (semejantísimo), el aumentativo y despectivo semejantote (cf. 12b), al menos actúa como atenuador, y con el aumentativo semejantona, en su valor de crítica o de ironía (cf. 12c):

(12) a. Lucas McMiller dice: La verdad, no suelo escuchar este tipo de música, pero qué es lo peor que me pueda pasar? Lo único que escuché semejantito es un CD de Rick Wakeman ("Ayreon, el Universo y la ciencia», Taringa.net, 2011, Argentina).

b. Una pregunta seria... cómo hace un escolta para proteger a semejantote blanco amarillo («Maduro caminó anoche por la avenida Urdaneta», Noticiero digital.com, 15/01/2016, Venezuela).

c. ¡A eso no hay derecho! porque si hay que pagar, el hombre lo paga... pero sin factura... eso es más delicao... ¡que no ha sido culpa suya, mal pensaos!, ¡que 
el hombre ha ido ahorrando pa pagar semejantona reformona ( $¿$ Qué le ha parecido la nueva campańa del PSOE: «Con Z de Zapatero»?», Libertad digital.com, 18/10/2007, España).

Por lo que respecta a su forma negativa, desemejante ('diferente, no semejante') no es empleado con mucha frecuencia en español actual'; ; en el CORPES XXI se documentan solo veinte casos. Se suele construir con la preposición de (Seco 1998: 159) pero también se registra con $a$ (cf. 13b):

(13) a. De esa situación desemejante se derivan también problemas distintos. Los que implican la urbanización y el sostenimiento de los poblamientos agrícolas son mucho menos complejos y de más fácil solución (La tierra humanizada, Leoncio Urabayen, 1949, España).

b. El quechua ayacuchano es desemejante al cuzqueño. El primero está colmado de virilidad; el segundo derrama ternura (Paisajes natural y cultural del Perú, Leónidas Castro Bastos, 1971, Perú).

El adverbio semejantemente ('con semejanza') por su parte, es de poco uso en español actual. En el CORPES XXI se documenta un solo caso y en la versión anotada del CREA cuatro casos. Los ejemplos de (13) muestran su valor anafórico, empleado para referirse a una situación anterior. Hoy en día se prefiere su paráfrasis, la locución de manera semejante (a) (RAE 2017), o el adverbio igualmente.

(14) a. Me refiero, en primer lugar, al movimiento de las Comunidades, del que hace unos años ofrecí una interpretación que, insertándolo en la línea de los procesos conflictivos del siglo XVI en la Península ibérica, proponía ver en él, semejantemente a los de otros muchos países europeos, una primera manifestación de enfrentamiento revolucionario (Las comunidades de Castilla, José Antonio Maravall, 1979, España).

b. asumir un tratamiento universal, a través de mecanismos sociales y económicos convencionales, que han sido acertadas en otras poblaciones, funcionará semejantemente entre las poblaciones indígenas (Trabajo infantily pueblos indígenas. El caso de Panamá, Gabriela Olguín Martínez, 2006, México). c. las despiadadas deducciones del Descifrador lo sumergían progresivamente en el desconcierto más absoluto, haciéndolo caer en la trampa de sus propias y frenéticas palabras de manera semejante a esos lagos de podredumbre que -según diversos testimonios de viajeros con los que había hablado- engullen con más rapidez (La caverna de las ideas, José Carlos Somoza, 2000, Cuba).

\footnotetext{
5 También lo es el adjetivo disímbolo ('disímil, diferente'), adjetivo que aparece marcado como 'desusado' en el Diccionario de la lengua española (RAE 2017), pero que es común en países como México (ASALE 2010).
} 
Por último, en el habla rural de informantes mayores hemos documentado un uso de semejante, registrado en los datos del COSER (Corpus Oral y Sonoro del Español Rural) -hasta ahora solo en algunos enclaves de la Comunidad de Madrid y en la provincia de Ciudad Real-, en donde este adjetivo parece emplearse como adverbio. Esta recategorización de adjetivo a adverbio de semejante, en el sentido de conversión (Demonte 2000), no había sido señalada con anterioridad en ningún trabajo gramatical. Aunque son escasos, y por el momento no disponemos de más documentación, los ejemplos de (15) muestran una interpretación y un uso sintáctico de semejante diferentes a lo presentado en los ejemplos (1-14) y es esta nueva conceptualización ('de manera similar, de la misma manera, igualmente'; 'también'; 'por ejemplo, tal que') la que le permite actuar como adverbio. En todos estos casos semejante aparece junto a un adverbio de lugar (aqui, cf. $15 \mathrm{a}$ y b), de modo (así, cf. 15b) o con ambos a la vez (cf. 15c). En estos casos sirve para modificar a estos otros adverbios, sin perder la posibilidad de modificar al predicado (como argumental):

(15) a. E: Y para sujetar a las ovejas, ¿qué? I: Sí, yo he esqui-, sí yo he esquilao unas cuantas que tenía, vamos, pero a mí... E: Propias. I: Sí, y entonces, pues ya, ya, bueno, pues yo, yo, yo las he, he cogido y las tumbaba, coges de las patas y como te amañas tuvieras, tenías que tumbar a la oveja, la oveja tripa arriba, el cuello aquí, la cabeza semejante aquí y... las patas pa abajo (COSER-2914, Sieteiglesias, Madrid, 1995, H, 75).

b. I1: Ese esparto iba dando vueltas y cogía la | el que lo hacía, el hombre o la mujer, cogía así un cacho, y lo metía semejante así, en el, en el, en el centro este y nada, yo voy aprestando, aprestando, aprestando, hasta que ya no se podía, ya no cogía más, y entonces, pues ya, al ya no coger más, pues ese la retiraban y ponían, por ejemplo, semejante aquí, otro aquí, otro aquí, como | que en una | encima de una mesa y luego ponían áhi una piedra (COSER-2914, Sieteiglesias, Madrid, 1995, H, 75).

c. I: Eso es, o sea, se, las turmas esas, las venas que tienen esas son gordas y entonces... yo, me parece que llegué a machacar con un almidez, ponía las turmas así, semejante con un palo así, semejante así aquí, y con un palo, o $\mathrm{u}-$, o una mano de almidez, machacaba las venas que tienen, y al machacarlas, pues eso ya se quedaba seco (COSER-2914, Sieteiglesias, Madrid, 1995, H, 75).

Como puede comprobarse en los ejemplos precedentes, semejante presenta un valor 'anafórico' que hace referencia a una situación inmediatamente anterior, de modo que la paráfrasis de "el cuello aquí, la cabeza semejante aquí» de (15a) sería 'el cuello aquí, la cabeza de manera semejante/tal que aquí y la paráfrasis de (15b) «y lo metía semejante así» sería 'y lo metía de esta manera así/por ejemplo en el centro’ o 'lo metía también así 
en el centro'. Como adverbio, por tanto, semejante puede denotar manera, pero también un uso discursivo 6 .

Por otro lado, la adverbialización no es nueva en español. En efecto, a lo largo de la historia de la lengua se puede documentar algunos casos en los que semejante aparece complementando a un verbo con el mismo sentido de 'de la misma manera' (cf. 16a, en referencia a un sustantivo tácito como hecho) o iguall igualmente (cf. 16b, en referencia a decir) que hemos visto en (15):

(16) a. Por cierto, echo increýble, que ni del bravo Alceo, ni de Milón Cretense se escrivió semejante (Varia fortuna del soldado Pindaro, Gonzalo de Céspedes y Meneses, 1626).

b. Plinjo dize que el Cauallo es bestia muy fiel alos hombres. Asy como el perro. E ha grant presagio/o adiujnamjento de las batallas/ quales deuen vençer/ o ser vençidos. Quando pierden su señyor ploran/ ysidro dize semejante (Tratado de Agricultura, Paladio, tr. anónimo, s. XIV).

La adverbialización del adjetivo semejante implica, por tanto, dos usos diferentes: un uso 'discursivo' (cf. 15), donde semejante modifica a otro adverbio; y un uso adverbial predicativo (cf. 16), sin llegar a formar un predicado complejo (Hernando Cuadrado 2006: 38, RAE/ASALE 2009: 2296). La documentación de casos como "Claudia habla semejante» (COLEM-México, 2015, M, 27) en donde semejante modifica al verbo -con el sentido de 'Claudia habla de manera similar o parecida'- como lo harían los adverbios parecido o igual en Claudia habla parecido/igual, empieza a registrarse en algunas variedades del español actual 7 . La Academia, por su parte, mantiene que la adverbialización de adjetivos en español está limitada a un número reducido y posee más vitalidad en el español americano (RAE/ ASALE 2009: 2296). Admite la adverbialización de parecido (Suenan parecido) y de igual (Los dos me gustan igual), sobre la base de adjetivos que expresan similitud y diferencia (RAE/ASALE 2009: 2299), pero no menciona el caso de semejante. Suñer y Di Tullio (2014: 23), por su parte, denominan a los adjetivos adverbiales como "adjetivos desnudos", muestran la relación que existe entre la manera y el aspecto y consideran la recategorización un epifenómeno.

\footnotetext{
6 Seco, Ramos y Andrés (1999: 4066) indican un uso «raro» de semejante -con el sentido de 'semejanza'- en casos como el siguiente: «La Calleja de las Flores se pone ante el viajero sin que este lo advierta y, a semejante de esos escondidos remolinos de los ríos de la Sierra, lo atrae con fuerza irresistible» (José M. Salcedo Córdoba, Cultura popular y Cristianismo, 1970).

Solo la documentación amplia del fenómeno podrá precisar si en todos los casos de este nuevo uso se supone un sustantivo tácito o no (Claudia habla (un español) semejante (al de Elena)), al igual que en (16a), por ejemplo.
} 


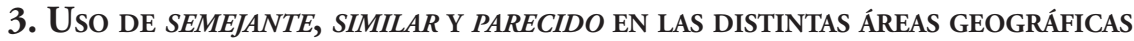

Hasta ahora hemos revisado la gramática del adjetivo semejante de manera independiente. En lo que sigue estableceremos un breve contraste con los adjetivos similar ('que tiene semejanza o analogía con algo', RAE 2017) y parecido ('dicho de una persona o cosa, que se parece a otra', RAE 2017) para dar a conocer sus frecuencias de uso en las distintas variedades del español actual, ya que presentan un significado y unos contextos de aparición que pueden ser equivalentes ${ }^{8}$. Todos los trabajos lexicográficos consultados los dan como sinónimos (cf., entre otros, Moliner 2007: 2684). Los ejemplos de (15) muestran este hecho':

(17) a. Nos daba vergüenza el hecho de que el Papa había recorrido ya todo el mundo y no había aún venido aquí. Y así nos decidimos al final a invitarlo, aunque no sabíamos si podríamos afrontar, siendo tan exiguos, una empresa semejante («El Papa emprende su viaje a los países nórdicos», El País, 01/06/1989, España).

b. Carlos Rodiles fue quien formó la empresa Unique Gems, cuyas operaciones comenzaron en 1995 en las oficinas de Spanish Foods en Miami, una empresa a su nombre dedicada a la importación de alimentos española. Harry Abonde, que al parecer también se logró fotografiar junto al presidente norteamericano, Bill Clinton, había sido acusado en 1987 en Reino Unido de organizar otra empresa similar ("Tres residentes en Marbella, implicados en una estafa piramidal», El País, 27/08/1997, España).

c. En el año 39, cuando los alemanes invadieron, mi padre estaba bastante enfermo, por el asma. Pero en el año 37 o 38, cuando vio que había peligro, vendió la mayor parte de su astillero a una empresa parecida a la CAP, que le hizo un contrato vitalicio para mantenerlo como gerente general (Hoy, 0309/11/1997, Chile).

\footnotetext{
8 Otros posibles sinónimos -en algunos de sus usos (cf. RAE 2017)- serían los adjetivos afín, análogo, aproximado, cercano, coincidente, comparable, correspondiente, emparentado, equilibrado, equivalente, idéntico, igual, paralelo, parangonable, parejo, próximo, relacionado o símil. Dejamos para un futuro trabajo el estudio y la comparación de todos ellos.

$9 \quad$ Otros ejemplos más concretos figuran en el propio Diccionario de la lengua española (RAE 2017). En efecto, a la hora de definir el siu, se puede leer "pájaro americano muy semejante al jilguero", en la definición de taruga «mamífero rumiante americano parecido al ciervo» y en la de tarima «suelo similar al parqué». Su uso en posición inicial también es otro contexto sinonímico: «la historia y el objeto de tan sencillos monumentos se perpetúan tradicionalmente de época en época. Semejante fue el propósito de llevar las doce piedras a Gilgal: para que fueran un permanente recuerdo del milagroso paso del Jordán» (Comentario exegético y explicativo de la Biblia, Roberto Jamieson et al., Colombia, 2006).
} 
Para conocer la frecuencia de uso de los adjetivos semejante, similar y parecido en las diferentes zonas geográficas empleamos los datos del CORPES XXI ${ }^{10}$. La tabla 1, a continuación, nos muestra en la primera de las columnas de cada una de estas formas la frecuencia conjunta, y en la segunda de las columnas su frecuencia normalizada. La frecuencia conjunta representa los casos totales documentados en el corpus y la frecuencia normalizada el número de ocurrencias de cada adjetivo por cada millón de palabras en cada una de las siete áreas consideradas.

Tabla 1. Frecuencias de aparición de los adjetivos semejante, similar y parecido, según el CORPES XXI

\begin{tabular}{|l|r|r|r|r|r|r|r|}
\hline & \multicolumn{2}{|c|}{ Semejante } & \multicolumn{2}{c|}{ Similar } & \multicolumn{2}{c|}{ Parecido } \\
\hline 1. Espańa & $\mathbf{3 6 6 0}$ & 46,17 & $\mathbf{7 6 8 4}$ & 96,93 & $\mathbf{1 0 7 8}$ & $\mathbf{1 3 , 5 9}$ \\
\hline 2. México y Centroamérica & 1955 & 43,83 & 4332 & 97,12 & 388 & 8,69 \\
\hline 3. Río de la Plata & 1465 & 45,88 & 3015 & 94,42 & 358 & 11,21 \\
\hline 4. Caribe continental & 1318 & $\mathbf{4 7 , 9 7}$ & 2412 & 87,79 & 250 & 9,09 \\
\hline 5. Antillas & 691 & 37,39 & 1912 & 103,46 & 172 & 10,41 \\
\hline 6. Andes & 571 & 34,57 & 1852 & 112,14 & 164 & 8,87 \\
\hline 7. Chile & 351 & 24,48 & 1703 & $\mathbf{1 1 8 , 7 7}$ & 149 & 10,39 \\
\hline Totales & $\mathbf{1 0 ~ 0 1 1}$ & & $\mathbf{2 2 ~ 9 1 0}$ & & & $\mathbf{2 5 5 9}$ & \\
\hline
\end{tabular}

Si nos detenemos, en un primer momento, en los totales presentados en esta tabla vemos que similar es la forma más empleada de las tres (con 22910 casos), seguida por semejante (con 10 011). El adjetivo parecido es el menos empleado de todos (con 2559 casos).

En segundo lugar, y por lo que respecta a semejante, aunque en Espańa es donde se registran más casos de este adjetivo (3660) y en Chile donde menos (351), la frecuencia normalizada nos dice que es el Caribe continental el área donde mayor uso se hace de dicho adjetivo (con 47,97), seguido de cerca por España (46), el Río de la Plata (45) y MéxicoCentroamérica (43). En cuanto a similar, de nuevo es España el área en donde más casos se registran y Chile el área en donde menos (7684 vs. 1703, respectivamente), pero es justo en Chile donde la frecuencia normalizada es más alta (118,77 ocurrencias por millón), seguida por los Andes (112) y las Antillas (103). Por último, en cuanto al adjetivo parecido, Espańa presenta el mayor número de casos (1078) y Chile el menor (149), sin embargo es

\footnotetext{
10 Para la confección de la tabla no se ha tenido en cuenta los casos registrados en otras áreas como Guinea Ecuatorial, Filipinas y los Estados Unidos.
} 
en España donde la frecuencia normalizada es mayor (13,59), seguida por el Río de la Plata (11), las Antillas (10) y Chile (10).

En resumen, lo interesante de estos datos -a nuestro modo de ver-, además de mostrar la pertinencia y el valor del CORPES XXI para el estudio de la lengua española, es que los tres adjetivos en cuestión presentan una distribución geográfica diferente. En efecto, mientras que unas áreas, como Chile y los Andes, emplean con mayor proporción el adjetivo similar, otras como el Caribe continental y España hacen lo mismo con semejante. El uso del adjetivo parecido, por último, es más equilibrado y su frecuencia de uso es muy reducida en todas ellas.

Por lo que respecta a su uso, señalamos de manera sucinta que similar se suele aplicar preferentemente a cosas, mientras que parecido y semejante se pueden emplear tanto para personas como para cosas (cf. Diccionario actual de la lengua española 1996: 1440). Otro dato en cuanto al uso de estos adjetivos es que parecido se construye generalmente con la preposición de (Moliner 2007: 2187), como en Son parecidos de estatura, pero también admite la construcción con en, como en Es parecido en los ojos (cf. lo visto para semejante en los ejemplos de 8).

\section{ConClusiones Finales}

Como indica Bosque (2012: 93, n. 1), el adjetivo semejante es uno de los elementos que denota la identidad en español ${ }^{11}$. Como tal, sirve para presentar individuos, propiedades o grupos en función de su identidad o igualdad, una veces en relación a la cantidad otras a la cualidad de la noción introducida por el sustantivo (RAE/ASALE 2009: 1206).

Este trabajo ha ofrecido un compendio de algunas de sus propiedades gramaticales más relevantes, en cuanto a su significado y posición con respecto al sustantivo que acompańa. Por lo que respecta a sus significados, cuando semejante aparece antepuesto al sustantivo puede actuar como adjetivo indefinido, con valor identificativo, cuantificador y determinativo (semejante asunto), y cuando figura pospuesto al sustantivo puede ser adjetivo calificativo, con valor restrictivo (un asunto semejante equivale a 'un asunto como ese', 'un asunto asî'). El significado equivalente a grande o enorme 'de gran tamaño' (semejante animal) o 'de gran nivel' (semejante pibón), que deriva de su valor cuantificador, todavía no aparece recogido en el Diccionario de la lengua española (RAE 2017), y el Diccionario de americanismos (2010) solo lo incluye para el caso de Honduras. El valor cuantificativo

\footnotetext{
11 Bosque (2012) se centra en el estudio del adjetivo mismo. El autor identifica un uso anafórico o externo, donde el antecedente del adjetivo está en el discurso previo, por tanto la referencia se recupera directamente del contexto, como en Juan vive en Zagreb. Hace unos años, su hijo vivía en la misma ciudad; y un uso dependiente o interno, que requiere una expresión en plural en su entorno sintáctico, por tanto la referencia se construye relacionando las piezas léxicas que aparecen, como en Mis tres hermanos estudiaron en el mismo colegio. Bosque propone que en este segundo caso mismo se acerca a los indefinidos, por lo que puede ser tratado como uno de ellos.
} 
('tan') viene del cualificativo ('tal'), ya que ambos pueden ser escalares. Este empleo como cuantificador ponderativo, sobre todo usado en plural y en posición prenominal (Tenía semejantes/tales/ tantas ganas de verte) convive con su uso singular (Se dio semejante golpe que tuvo que ser ingresado en el hospital). Es decir, al valor demostrativo ('un golpe así, un golpe como ese, de ese tipo') algunos hablantes ańadirían el valor ponderativo ('un golpe de una magnitud tal que/tan grande que'), generalmente con ascenso en el tono de lo enunciado.

Por otro lado, en su construcción con preposición el adjetivo semejante se inclina por a (aunque también hay casos documentados con la preposición de). Permite ser modificado por sufijos apreciativos (semejantote) y su forma negativa (desemejante) es muy poco empleada en espańol actual, así como el adverbio semejantemente.

Además, hemos visto que semejante puede adquirir también un valor adverbial 'discursivo'. Esta recategorización parece ser incipiente en español actual peninsular, aunque se registran casos con valor predicativo ya en espańol medieval y clásico. Este uso sintáctico no había sido descrito con anterioridad.

Finalmente, la comparación con otros adjetivos con los que presenta un significado afín (similar y parecido) nos ha mostrado que el CORPES XXI es una herramienta muy útil para el estudio del espańol actual y que estos tres adjetivos tienen un uso diferente en las distintas áreas geográficas hispanohablantes, sobre todo similar y semejante.

\section{Obras CiTADAS}

Asociación de Academias de la Lengua Española. 2010. Diccionario de americanismos. Lima: Santillana. Disponible en línea: www.asale.org

Bello, Andrés. 1883. Gramática de la lengua castellana. Obras completas de Don Andrés Bello, vol. IV. Santiago de Chile: Pedro G. Ramírez.

Bosque, Ignacio. 2012. "Sobre el adjetivo mismo en las construcciones de dependencia interna”. T. Jiménez Juliá et al. (eds.), Cum corde et in nova grammatica. Estudios ofrecidos a Guillermo Rojo. Santiago de Compostela: Universidad de Santiago de Compostela. 93-108.

CREA, Corpus de referencia del español actual. Madrid: Real Academia Española. Disponible en línea: www.rae.es

CORPES XXI, Corpus del Español del Siglo XXI. Madrid: Real Academia Española. Disponible en línea: www.rae.es

Davies, Mark (dir.). 2005-2016. Corpus del español. Provo, UT: Brigham Young University. Disponible en línea: corpusdelesapnol.org

Demonte Barreto, Violeta. 2000. "Gramática, variación y norma. Una tipología”. Estudios Hispánicos. Revista de la Sociedad Coreana de Hispanistas 17.12: 3-49.

Diccionario actual de la lengua española. 1996. Lincolnwood, Chicago: NTC Publishing.

Diccionario del español de México (DEM). 2016. Ciudad de México: El Colegio de México. 
Disponible en línea: dem.colmex.mx

Diccionario para la enseñanza de la lengua española. Español para extranjeros. 2007. Alcalá de Henares/Barcelona: Universidad de Alcalál Larousse.

Fernández-Ordónez, Inés (dir.). 2005-2018. Corpus Oraly Sonoro del Español Rural-COSER. Madrid: Universidad Autónoma de Madrid. Disponible en línea: corpusrural.es Hernando Cuadrado, Luis Alberto. 2006. Gramática del adverbio en español. Madrid: Universidad Rey Juan Carlos/ Ed. Dykinson.

Lara, Luis Fernando (dir.). 1996. Diccionario del español usual en México. Ciudad de México: El Colegio de México.

Moliner, María. 2007. Diccionario de uso del español. Madrid: Gredos, 2 vols.

Pato, Enrique (dir.). 2013-2018. Corpus oral de la lengua española en Montreal-COLEM. Montreal: Université de Montréal.

Real Academia Española. 2017. Diccionario de la lengua española. Edición del Tricentenario. Madrid: Espasa. Disponible en línea: www.rae.es

Real Academia Española y Asociación de Academias de la Lengua Espańola. 2009. Nueva gramática de la lengua española. Madrid: Espasa.

Seco, Manuel. 1998. Diccionario de dudas y dificultades de la lengua española. Madrid: Espasa.

Seco, Manuel, Gabino Ramos, Olimpia Andrés. 1999. Diccionario del español actual. Madrid: Aguilar, 2 vols.

Suñer, Avellina, Ángela Di Tullio. 2014. "Bare adjectives as syncretic forms". Borealis: An International Journal of Hispanic Linguistics 3.1: 23-47. 